\title{
A meta-analysis and bibliographic review of the effect of nine factors on online learning outcomes across the world
}

\section{Zhonggen $\mathrm{Yu}^{1}{ }^{10}$}

Received: 25 May 2021 / Accepted: 16 August 2021 / Published online: 23 August 2021

(c) The Author(s), under exclusive licence to Springer Science+Business Media, LLC, part of Springer Nature 2021

\begin{abstract}
The unpredictable pandemic has drastically altered learning approaches, where online learning has been booming. Through VOSviewer, this study visualizes the network of top authors, organizations, sources, and countries that have been devoted to online learning. Through meta-analyses via Stata/MP 14.0, this study identifies nine variables that may exert a significant effect on online learning outcomes during this special pandemic time in various countries and areas. The findings may be generalizable to America, Asia, and Europe. Although relatively fewer publications in Africa have been included, the findings could provide a meaningful reference for African researchers and practitioners. Future research could include more publications from more diversified backgrounds. Online learning design could also keep pace with the development of information technologies.
\end{abstract}

Keywords Meta-analysis · Bibliographic review · Online learning $\cdot$ Influencing factors $\cdot$ Pandemic

\section{Introduction}

The COVID-19 pandemic has greatly influenced educational approaches across the world, leading to many studies devoted to online learning during this special time. Most of them reported positive online learning outcomes. In the online student-centered learning, a teacher could provide individualized instruction based on teacher-student interactions and communication, where teacher feedback could improve students' learning outcomes and enhance their engagement. Remote feedback, together with a contextualized and situated approach, is considered essential

Zhonggen $\mathrm{Yu}$

401373742@qq.com; yuzhonggen@blcu.edu.cn

1 Department of English Studies, Faculty of Foreign Studies, Beijing Language and Culture

University, Beijing, China 
in online learning (Istenic, 2021). The COVID-19 pandemic, minimizing the differences in perceived personal relevance and online learning feasibility, has substantially increased attainment value, utility value, mastery-approach goal, masteryavoidance goal, performance-avoidance goal, and functional self-efficacy of online education since its outbreak (Lin, 2021).

The pandemic time has experienced positive online learning outcomes. Both students and teachers would like to learn through the Internet in the future since both of them positively evaluated online learning (Schlenz et al., 2020). Online learning could decrease negative learning emotions and increase learning engagement (Basal \& Eryilmaz, 2020). Students maintained an intense interest in the flipped online learning approach (Jia et al., 2020). Online learners highly evaluated supportive online instruction and motivational strategies because they could improve their learning performance (Yates et al., 2020). During the pandemic time, students began to accept the online learning approach and their major concerns were network availability, comfort, network connectivity, online learning outcomes, online learning contents, and student-instructor online interactions (Kamble et al., 2021). Social media such as TikTok could improve learners' perceptions of online learning during the pandemic (Literat, 2021).

There are a variety of factors that can exert an influence on online learning outcomes. The level of communication capacities and self-organization skills could exert a positive influence on perceived academic achievements in an online learning context (Klein et al., 2021). Variables such as direct lectures, instructor-learner interaction, internet self-efficacy, mediated by online learning motivation, could predict students' satisfaction with online learning (Rahman et al., 2021). Self-regulation, interaction, engagement, and interest are important factors to ensure the online learning effectiveness. Students prefer the traditional face-to-face learning to the online learning although the majority of them feel satisfied with the online learning approach (Huang, 2020).

However, negative effects and challenges of online learning have been revealed in previous studies. Some students $(36.8 \%)$ preferred traditional face-to-face learning to merely online learning. Algerian university students negatively evaluated online learning. They preferred the traditional face-to-face learning approach to the online learning mode even during the pandemic (Blizak et al., 2020).

Few studies have focused on bibliographic review and meta-analysis regarding the effect of various factors on online education. It is thus necessary to review the recent online learning and teaching integrated with information technologies (Carrillo \& Flores, 2020) via a meta-analysis and bibliographic review.

\subsection{Data collection for the bibliographic review}

We obtained 6971 results from Web of Science (Core Collection) by entering title: ("online learn*" OR "online teach"” OR "online educat*" OR "distance learn*" OR "distance teach*" OR "distance educat*" OR "digital learn*" OR "digital teach" OR "digital educat*") without limitation to publication time in the databases. Web of Science includes several databases such as Science Citation Index Expanded 
(SCI-EXPANDED) (from 1998 to 2021), Social Sciences Citation Index (SSCI) (from 2016 to 2021), Conference Proceedings Citation Index- Science (CPCI-S) (from 1991 to 2021), Current Chemical Reactions (CCR-EXPANDED) (from 1985 to 2021), and Index Chemicus (IC) (from 1993 to 2021). We finally included 2412 results for bibliographic analysis after removing the unrelated publications.

Links and total link strength are used to measure the association of a given item with other items. The former indicates the number of associations of the given item with others, while the latter indicates the total weights of the associations of the given item with others. A citation link refers to the association where one given item cites another. This association is of no direction. In other words, we cannot conclude from the association that the given item predicts another or vice versa. A co-citation link refers to the association where two items are cited by the same literature, while a bibliographic coupling link refers to the association between two items that cite the same literature (Van Eck \& Waltman, 2019). The distance in the visualized map roughly indicates the strength of the relationship between co-citation links (Van Eck \& Waltman, 2010).

We obtained the top 10 co-cited authors through co-citation analysis. The minimum number of citations of an author was set at 22. Of the 38,938 authors, 157 met the threshold. For each of the 157 authors, the total strength of the co-citation links with other authors was calculated. The authors with the greatest total link strength were selected. The top 10 co-cited authors were Garrison, D.R. (Citations $=191$, Total link strength $=1583)$, Zimmerman, B.J. $($ Citations $=114$, Total link strength $=1156)$, Pintrich, P.R. (Citations $=115$, Total link strength $=1124)$, Rovai, A.P. $($ Citations $=104$, Total link strength $=952)$, Bandura, A. $($ Citations $=115$, Total link strength $=950$ ), Hair, J.F. (Citations $=81$, Total link strength=950), Moore, M.G. $($ Citations $=123$, Total link strength $=789)$, Mayer, R.E. $($ Citations $=110$, Total link strength $=771)$, Venkatesh, V. (Citations $=81$, Total link strength $=690)$, and

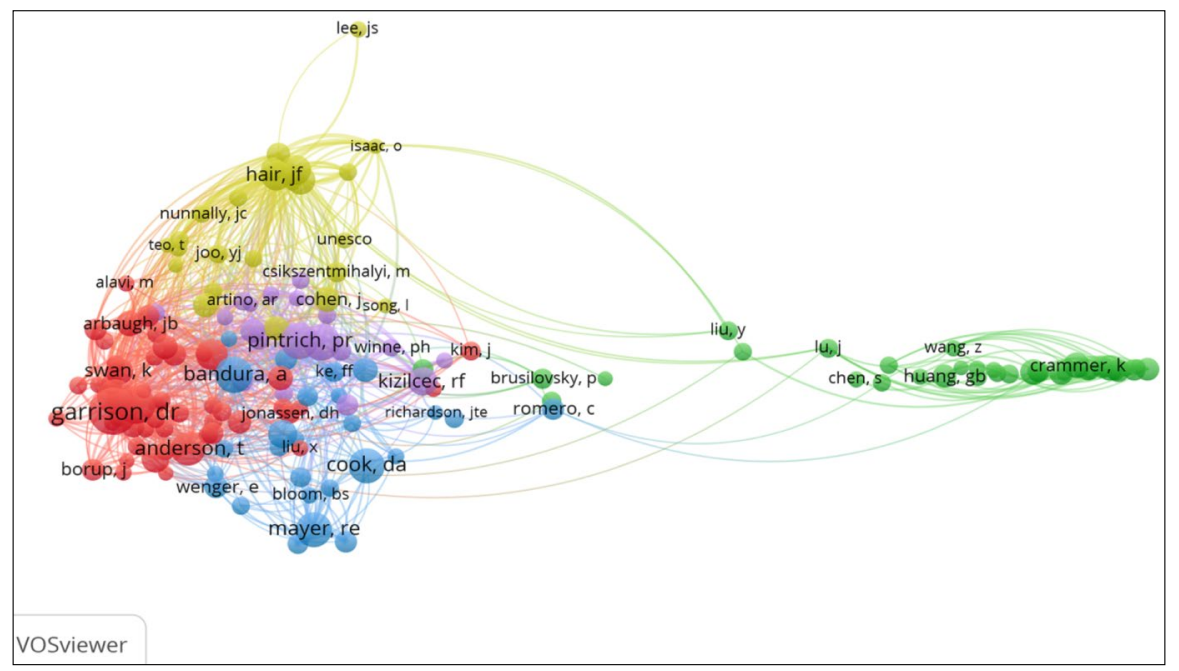

Fig. 1 The authors with the greatest total link strength 
Anderson, T. (Citations $=101$, Total link strength=671) (Fig. 1). It is indicated that these authors are among the most influential ones since they are co-cited by the most documents. Their works may draw additional attention when researchers conduct relevant studies.

We also analyzed highly cited organizations by selecting citation as the analysis type, and organization as the unit of analysis. The minimum number of documents of an organization was set at 6 . Of the 2171 organizations, 117 met the threshold. For each of the 117 organizations, the total strength of the citation links with other organizations was calculated. The organizations $(\mathrm{N}=117)$ with the greatest total link strength were selected. The top 10 organizations with the greatest total link strength were Nanyang Technological University (Citations $=180$, Total link strength $=20$ ), Open University of the Netherlands (Citations $=64$, Total link strength $=18$ ), University of California (Citations $=72$, Total link strength $=18$ ), Cornell University $($ Citations $=20$, Total link strength $=17)$, Harvard University $($ Citations $=109$, Total link strength=17), National Taiwan Normal University (Citations $=131$, Total link strength $=15)$, Imperial College London (Citations $=108$, Total link strength $=14$ ), Stanford University (Citations =209, Total link strength $=14$ ), Maastricht University (Citations $=27$, Total link strength $=11)$, and Ohio State University (Citations $=95$, Total link strength=11) (Fig. 2). It is suggested that these organizations have the highest citations and they have the highest total link strength that indicates the total link strength of co-citation links of a given organization with others. Researchers may pay enough attention to the authors affiliated with these organizations when they conduct related studies.

We obtained the highly cited countries through VOSviewer using similar methods. The top 10 countries with the greatest total link strength were USA (Citations $=6850$, Total link strength $=290$ ), The People's Republic of China (Citations $=1983$, Total link strength=161), England (Citations $=1063$, Total link strength $=157)$, Australia (Citations $=1010$, Total link strength $=119)$, Singapore

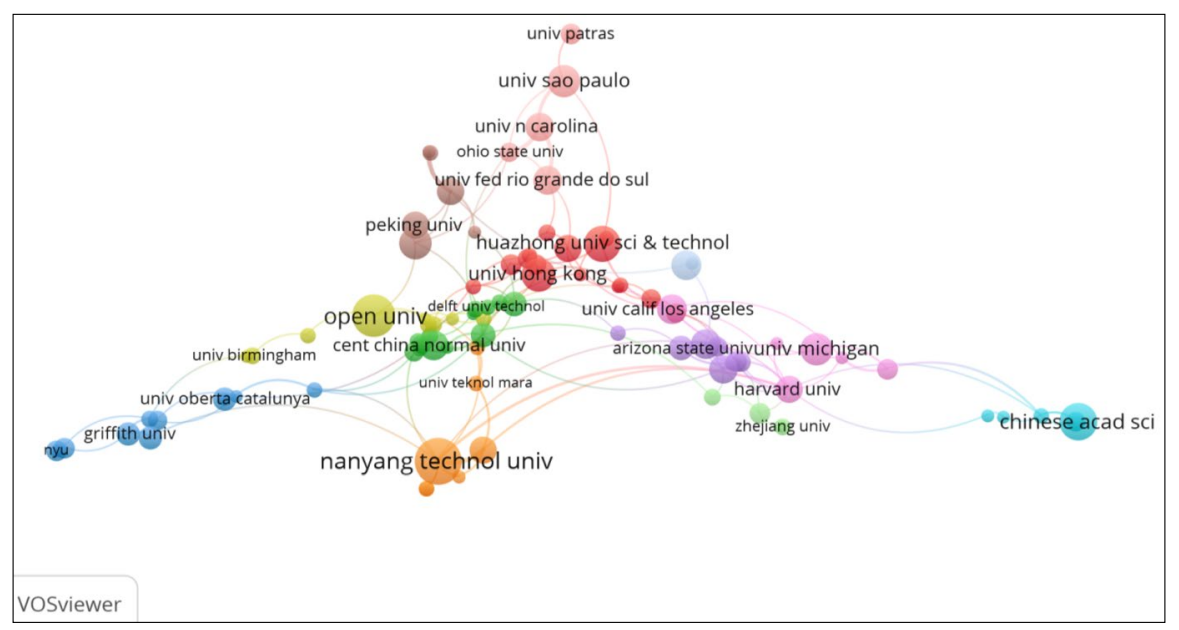

Fig. 2 The organizations with the greatest total link strength 
$($ Citations $=424$, Total link strength $=115)$, the Netherlands $($ Citations $=439$, Total link strength $=75)$, Turkey (Citations $=546$, Total link strength $=65$, South Korea (Citations $=414$, Total link strength $=49$, Canada (Citations $=784$, Total link strength $=46)$, and Switzerland (Citations $=205$, Total link strength $=46)$ (Fig. 3). It means that these countries may be focused on when researchers conduct online learning studies since publications from these countries have received the most citations.

\subsection{Co-occurrence analysis}

Co-occurrence links refer to the links between terms. VOSviewer can construct a map of keywords based on the data of co-occurrence to indicate the co-occurrence links (Van Eck \& Waltman, 2010). Via VOSviewer, we created a map based on the data retrieved from Web of Science. We selected co-occurrence as the analysis type, all keywords as the unit of analysis, and full counting as the counting method. The minimum number of occurrences of a keyword was set at 10. Of the 6556 keywords, 176 met the threshold. For each of the 176 keywords, the total strength of the co-occurrence links with other keywords was calculated. The keywords $(\mathrm{N}=176)$ with the greatest total link strength were selected. We selected nine variables with the greatest total link strength: behavioral intention (Occurrences $=25$, Total link strength $=115)$, instruction (Occurrences $=31$, Total link strength $=137$ ), engagement (Occurrences $=70$, Total link strength=276), interaction (Occurrences $=18$, Total link strength $=57$ ), motivation (Occurrences $=98$, Total link strength $=402$ ), self-efficacy (Occurrences $=60$, Total link strength=233), performance (Occurrences $=133$, Total link strength $=521$ ), satisfaction (Occurrences $=62$, Total link strength $=272$ ) and self-regulation (Occurrences $=23$, Total link strength $=102$ ) (Fig. 4).

Based on the bibliographic findings, we review previous studies on the topics closely related to the keywords with the greatest total link strength.

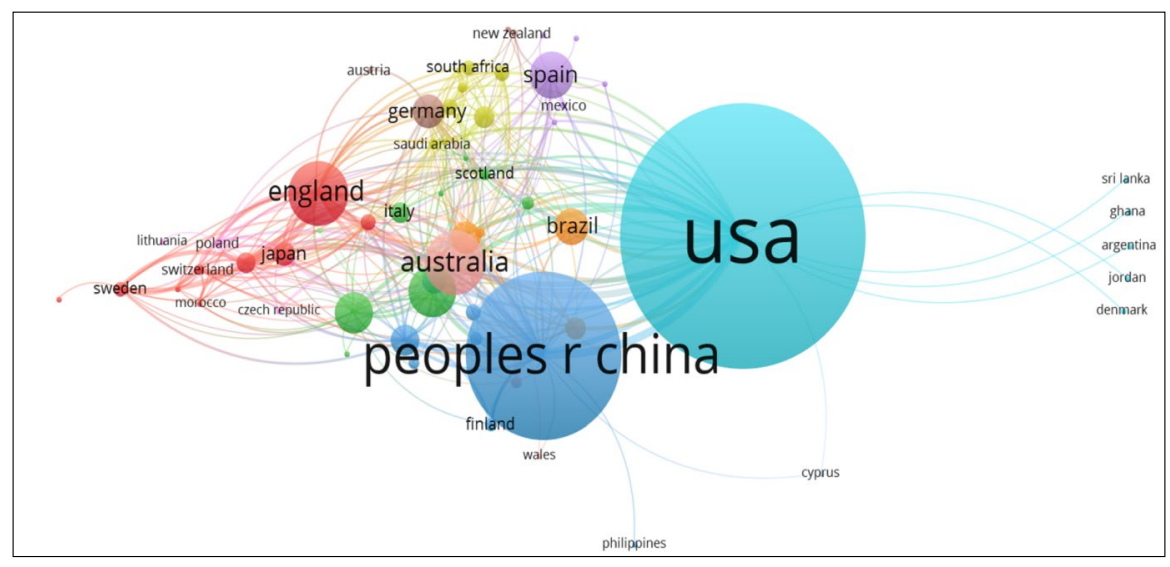

Fig. 3 The countries with the greatest total link strength 


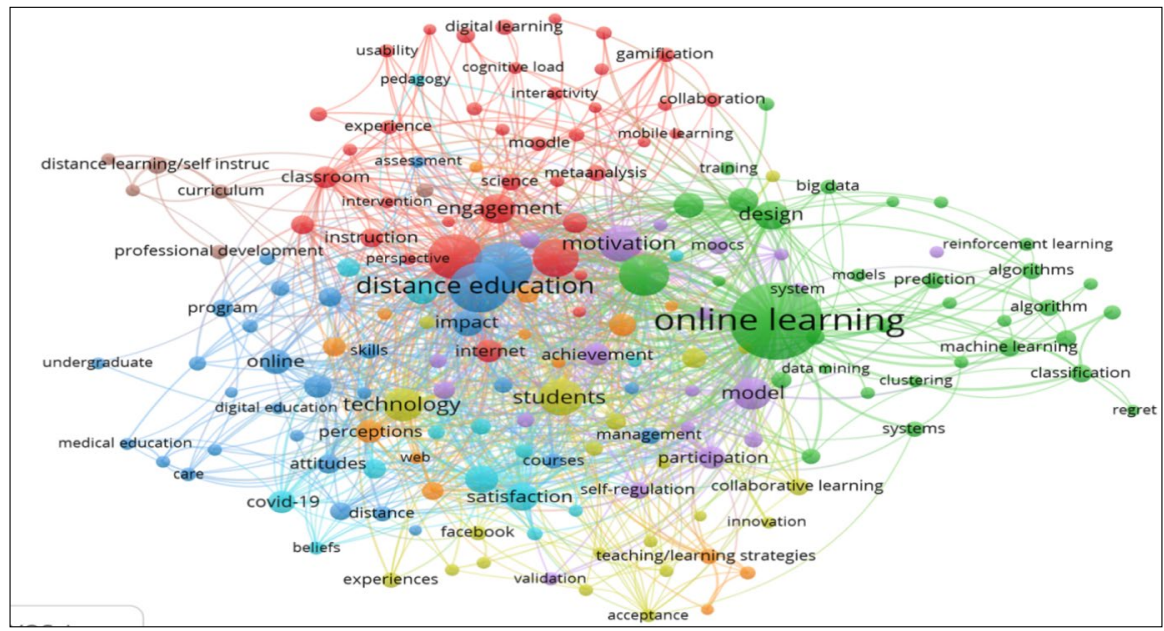

Fig. 4 Keywords with the greatest total link strength

\subsection{Behavioral intention}

Behavioral intention of online learning could be enhanced integrated with the entertainment element via computers or smart phones (Trepte \& Reinecke, 2010). Online computer games could improve behavioral intention of online learning and share with other players (Cohen, 2014). Online game-sharing portals could especially create an intriguing entertaining educational environment, which could improve learners' knowledge and enhance their behavioral intention of engagement in political programs (Roth et al., 2014) and information-seeking activities (Bartsch \& Schneider, 2014).

Although researchers (e.g., Guo et al., 2016) have argued that enhanced behavioral intention of online learning could improve learning outcomes, little is known about the connections between learners' engagement and behavioral intention of online learning. It has been reported that learners' behavioral attitudes may enhance behavioral intention of engagement in further online learning (Wu \& Chen, 2017). To identify the effect of online learning on behavioral intention, we, therefore, propose a null hypothesis as follows:

Hypothesis 1: Behavioral intention may be not significantly influenced by other factors in online learning.

\subsection{Instruction}

Instruction could exert a great influence on virtual online learning. However, one of the instruction elements, instructor immediacy, has been seldom explored. Instructor immediacy was referred to as the degree to which instructor-student communication could bridge the gap between instructors and students (Mehrabian, 1967), and 
remove the barriers to interpersonal communication (Thweatt \& McCroskey, 1996). Examples of instructor immediacy are addressing students by their nicknames, smiling, eye contacts, and follow-up enquiry. Instructor immediacy could greatly predict learning and teaching effectiveness (Anderson, 1979).

Instructive pace, flexibility, and accessibility are important factors influencing online learning effectiveness (McNamara, 2010). Plentiful instruction resources do not necessarily lead to increased use dependent on the source, frequency, and availability of the learning resources (Kinzie et al., 2015). Little is known about the relationship between instructional online support and instructors' development (Barton et al., 2017) although researchers have begun to devote their attention to online instructional activities (Paxton et al., 2013). Considering the previous research findings, we propose a null hypothesis as follows:

Hypothesis 2: Instruction may not significantly influence other factors in online learning.

\subsection{Engagement}

Engagement, subject to various elements, is considered an important factor that influences online learning effectiveness (Bradford, 2011). The level of cognitive loads may exert a great influence on learning engagement, and effective learning is also in need of cognitive engagement (Mayer \& Moreno, 2003). Learning engagement in an online course, in need of motivation and encouragement, is facilitated by various interactions, e.g. peer interactions, forum discussion, and student-teacher communications (Bradford, 2011).

Online lectures, discussions, tests, and interactions could enhance the level of engagement in online learning and facilitate academic success (Shrader et al., 2016). Self-efficacy, rather than learning persistence, could greatly influence online learning engagement (Jung \& Lee, 2018). Online learning engagement could be positively correlated with learners' self-regulation (Anders, 2015). Online learning success to a large extent depends on the degree of self-regulation (Terras \& Ramsay, 2015). Online learning engagement, positively correlated with online performance (Kim et al., 2021), could encourage learners to spend more effort and could thus play a critical role in online learning success (Tseng, 2018). Given the importance of online learning engagement, we propose a null hypothesis as follows:

Hypothesis 3: Engagement may not significantly influence other factors in online learning.

\subsection{Interaction}

Interaction plays an indispensable role in online learning outcomes. However, interactions in online learning have been reported insufficient due to different cultures among students and teachers (den Brok et al., 2010). Diversified online learning evaluation and interactions could predict online learning outcomes (Gallego Sánchez 
et al., 2021). Immersion in online learning environment could facilitate interactions between peers, teachers, and learning contents. Interactions could strongly predict the quality of online education (Gallego Sánchez et al., 2021) due to the relational coordination referring to a mutual process where interactions, communications, and correlations could be enhanced (Gittell, 2009). Given the significance of interactions in online learning, we propose a null hypothesis as follows:

Hypothesis 4: Interaction may not significantly influence other factors in online learning.

\subsection{Motivation and self-efficacy}

Motivation and self-efficacy are essential factors exerting a great influence on online learning outcomes (Yang et al., 2006; Chen \& Hu, 2020). Motivation, defined as the psychological state that facilitates, stimulates, or maintains learning behaviors (Woolfolk, 2016), is referred to as a process where learners set goals and strive for them (Pintrich \& Schunk, 2002: 5). Self-efficacy is considered learners' self-perception of their capacity of achieving online learning success (Chen \& Hu, 2020). Constructs of motivation are of variety, e.g. goal-setting, self-efficacy, and task worthiness (Yang et al., 2006). Highly motivated learners may be able to possess positive self-efficacy (Chen \& $\mathrm{Hu}, 2020$ ), maintain a fair interpersonal relationship, and obtain plentiful learning resources. They may also possess a high level of cognitive engagement in online learning. With timely feedback and strong motivators, synchronous online learning platforms could provide significantly more benefits than the traditional asynchronous approach (Chen et al., 2005). Learners' motivation levels could also greatly predict learning engagement in either online contexts or traditional conditions (Ben-Eliyahu et al., 2018). We, therefore, propose two null hypotheses as follows:

Hypothesis 5: Motivation may not significantly influence other factors in online learning.

Hypothesis 6: Self-efficacy may not significantly influence other factors in online learning.

\subsection{Performance}

Performance, as an important variable in online learning, may intertwine with many factors such as social factors, interactions, and feedback. Social factors such as social presence and interactions could greatly influence students' performance in terms of higher-order thinking abilities and academic scores (Al-Rahmi et al., 2018). Learners' performance is subject to learners' centrality in online algebra courses but no significant correlation is revealed between learners' centrality and their performance in the online finance course (Jiang et al., 2014). Their inconsistent findings are supported by Houston II et al. (2017) who argue that their correlation is not well clarified. 
Levels of motivation and feedback may greatly influence the correlations between learning engagement and learning performance (Steelman et al., 2004). However, feedback, either positive or negative, may worsen learners' performance (Kluger \& DeNisi, 1998) if it fails to promote learning behaviors (Scott et al., 1986). Learners' performance may also be under a great influence of their willingness to conduct revisions based on corresponding feedback, but little is known about whether learners tend to use their revision techniques in the unfamiliar learning tasks (Suzuki et al., 2019), which may negatively influence their learning performance. However, it is reported that critical feedback may encourage learners to revise learners' online posts, thus improving their learning performance (Cutumisu \& Lou, 2020). We propose a null hypothesis as follows:

Hypothesis 7: Performance may not significantly influence other factors in online learning.

\subsection{Satisfaction and self-regulation}

During this special pandemic time, online learning is widespread, where students' satisfaction and self-regulation have been demonstrated to play a critical role in online learning success (Joo et al., 2011; Puzziferro, 2008). Compared with traditional face-to-face learning, online learning may significantly improve students' satisfaction level, procedural and declarative knowledge (Means et al., 2013). Learners' satisfaction may be greatly influenced by the mentoring role and peer-mentor relationship (Grant-Vallone \& Ensher, 2000). Mentoring feedback and support may predict students' satisfaction with the mentoring function and learning contents (Sanchez et al., 2006). Instructors' self-disclosure such as self-introduction and posted photos may positively influence students' satisfaction with the instructorlearner relationship and quality of knowledge delivery, which may improve their online learning outcomes. In online learning, close relationships have been identified between self-regulation and learning outcomes (Barnard-Brak et al., 2010), engagement (Artino \& Stephens, 2009), and learners' level of satisfaction (Puzziferro, 2008). We thus propose two null hypotheses as follows:

Hypothesis 8: Satisfaction may not significantly influence other factors in online learning.

Hypothesis 9: Self-regulation may not significantly influence other factors in online learning.

\section{Methods}

Meta-analyses may be able to test the proposed null hypotheses by summarizing and quantifying previous research results. We implemented the meta-analysis based on the framework of the Preferred Reporting Items for Systematic Review and MetaAnalysis (PRISMA) (Moher et al., 2009). 


\subsection{Identifying research}

To minimize the biased results, we included research from various databases such as Web of Science, Taylor \& Francis Online, Elsevier ScienceDirect, Scopus, Ei Village, Emerald, SpringerLink, Wiley Online Library, and EBSCOhost. We searched these databases using corresponding terms according to their specific syntactic requirements. The searching terms include online learning, online teaching, online education, distance learning, distance teaching, distance education, digital learning, digital teaching, and digital education. The initial search returned a large number of results $(\mathrm{N}=30,253)$. We selected 3648 results after removing the duplication. Then through screening via reading abstracts and titles, evaluation for eligibility, and checking information and full texts for meta-analyses, we finally included 47 peerreviewed journal articles for the meta-analysis (Fig. 5).

\subsection{Inclusion and exclusion criteria}

We will include the studies if they (1) can provide enough information for a metaanalysis, (2) focus on the effects of nine variables in online learning or teaching, and (3) are of higher quality based on the criteria proposed by the University of the West of England Framework for Critically Appraising Research Articles (Moule et al., 2003), where two reviewers evaluate all the sections, i.e. the introduction,

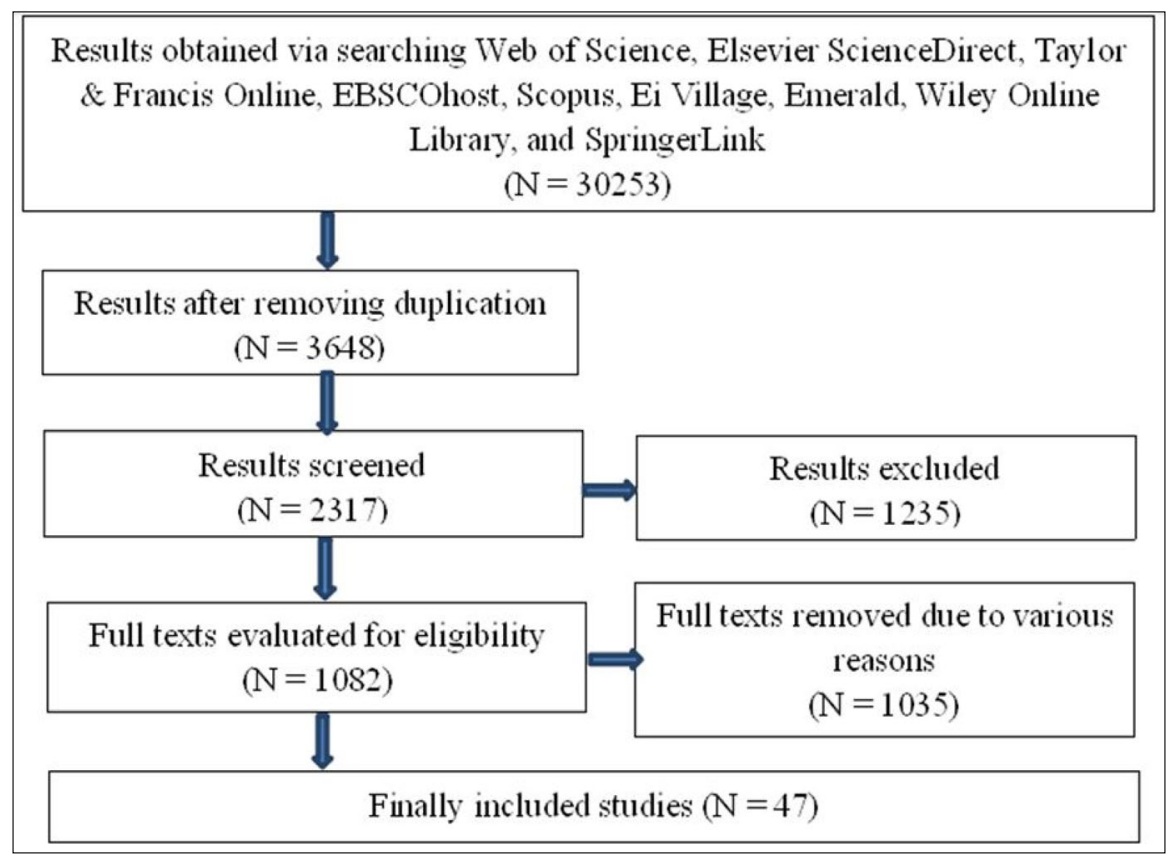

Fig. 5 A flowchart of literature inclusion 
methods, data collection and analysis, ethics, results or findings, and conclusions. The two reviewers are experienced in evaluating the quality of publications. They scored each study independently and informed the researchers of the results. In case two reviewers hold contradictory opinions, a third reviewer will be invited to make a decision.

We will exclude the studies if they (1) are written in a language other than English, (2) are poorly evaluated by two experienced reviewers based on the criteria proposed by the University of the West of England Framework for Critically Appraising Research Articles (Moule et al., 2003), (3) fail to provide enough information for a meta-analysis, or (4) are themselves review studies. If two reviewers have contradictory opinions, a third reviewer will be invited to decide the selection. If two reviewers held contradictory opinions on the quality of the study, we would invite a third experienced reviewer to make a final decision.

The enough data for a meta-analysis in this study include the number of participants, correlation coefficients, countries where the studies were conducted, online learning modes, and learning outcomes. The publication will be considered a review study if it aims to review or summarize recent studies in a particular field. A review study often synthesizes findings from the previous primary literature to develop a coherent argument about a given topic.

\subsection{Coding of studies}

The included studies were coded based on the scheme proposed by Siddiq et al. (2016). We coded the included studies by labeling them specific characteristics such as online learning modes, online learning outcomes, and countries. We also extracted meta-analytical data such as correlation co-efficiencies $(r)$ and numbers of participants, together with descriptive data such as publication years, countries where the studies were conducted, the subgroup including nine variables, and the mode of learning. Online learning, as the major mode of learning, was classified into blended, online, and electronic device- or online system-assisted learning.

\subsection{Statistical analyses}

We summarized the meta-analytical results using Stata/MP 14.0, where Z-statistics were adopted to analyze the overall effect sizes of influencing factors in online learning. Pearson's correlations $(r)$ were extracted to determine the relationship between online learning outcomes and behavioral intention, instruction, engagement, interaction, motivation, self-efficacy, performance, satisfaction, and self-regulation.

The percentage of variation across studies due to heterogeneity rather than random errors was identified through the value of $\mathrm{I}^{2}$, which was classified as unimportant when ranging from $0 \%$ to $40 \%$, moderate when ranging from $30 \%$ to $60 \%$, substantial when ranging from $50 \%$ to $90 \%$, and considerable when ranging from $75 \%$ to $100 \%$ (Higgins \& Green, 2011). When $\mathrm{I}^{2}$ is higher than $50 \%$, we will adopt a random-effect model to conduct a meta-analysis, as well as a sensitivity analysis to identify the stability of the result. When $\mathrm{I}^{2}$ is lower than $50 \%$, we will 
adopt a fixed-effect model to conduct a meta-analysis. To detect publication bias, we will adopt both Begg's (Begg \& Mazumdar, 1994) and Egger's tests (Egger et al., 1997).

Begg's test is an adjusted rank correlation test proposed by Begg and Mazumdar (1994) as a technique to test the publication bias in a meta-analysis, while egger's test aims to examine the absence or presence of asymmetry in a funnel plot comparing a small-size meta-analysis with studies of large samples (Egger et al., 1997). The fixed-effect model assumes that all the included studies share the same true effect size, while the random-effect model assumes that different included studies have different effect sizes.

\section{Results}

\subsection{Detection of publication bias}

We generated the standard errors of correlation coefficients before detecting the publication bias (Fig. 6). As shown in Fig. 6, an individual dot indicates a specific study. The $\mathrm{X}$-axis indicates the values of standard errors of Pearson's correlations, while the Y-axis indicates Pearson's correlations. The middle line indicates the no-effect line, while the lines on its either side indicate $95 \%$ confidence intervals. The dots are nearly symmetrically distributed along both sides of the middle line, which indicates the absence of publication bias (Kendall's Score $(\mathrm{P}-\mathrm{Q})=-493$, Std. Dev. of Score $=1158.88$ (corrected for ties), Number of Studies $=229, z=-0.43, \operatorname{Pr}>|z|=0.671)$. Egger's tests also indicate the absence of publication bias $($ Coefficient $=5.26$, Std. Error $=2.97, t=1.77, p=0.078)$.

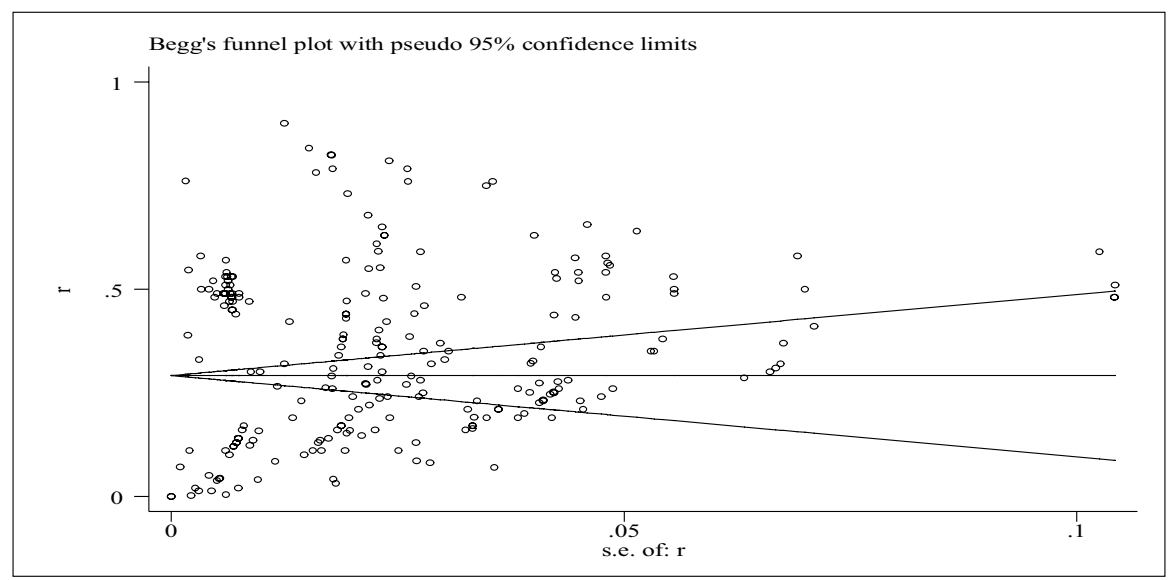

Fig. 6 A funnel plot of results of publication bias 


\subsection{The sensitivity analysis}

To conduct the sensitivity analysis, we entered "metaninf $\mathrm{r}$ ser, random" as a command and obtained Fig. 7. As shown in Fig. 7, each dot indicates a specific study. The middle line is the no-effect line, and two lines along its either side indicate the lower and upper $95 \%$ confidence intervals respectively. All the dots are located within $95 \%$ confidence intervals given a study is omitted. This indicates that the estimates of meta-analyses are stable and reliable.

\subsection{The effect of behavioral intention in online learning across the world}

We calculated seven effect sizes to study the effect of behavioral intention in online learning from China, South Korea, and Germany. We adopted a random-effect model since the percentage of variance of the effect sizes is due to heterogeneity rather than random errors $\left(\mathrm{Q}=6500.50, \mathrm{I}^{2}=99.9 \%, \mathrm{p}<.01\right)$. Significant effects were found in China $(\mathrm{z}=55.23, \mathrm{p}<.01)$, Germany $(\mathrm{z}=2.87, \mathrm{p}=0.004)$, and overall results $(\mathrm{z}=4.74, \mathrm{p}<.01)$, while not in South Korea $(\mathrm{z}=1.03, \mathrm{p}=0.301)$ (Fig. 8). Thus, we rejected Hypothesis 1: behavioral intention may be not significantly influenced by other factors in online learning.

\subsection{The effect of instruction in online learning across the world}

We calculated 11 effect sizes to study the effect of instruction in online learning from the USA, Austria, Australia, and China. We adopted a random-effect model since the percentage of variance of the effect sizes is due to heterogeneity rather

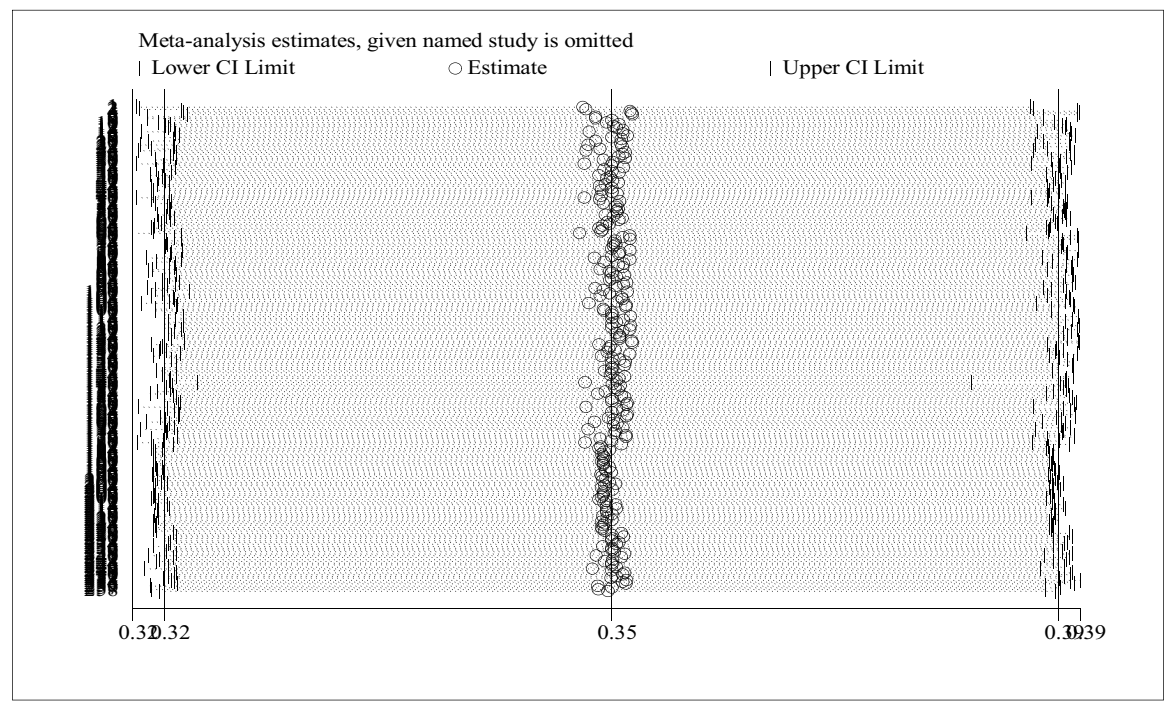

Fig. 7 Results of the sensitivity analysis 


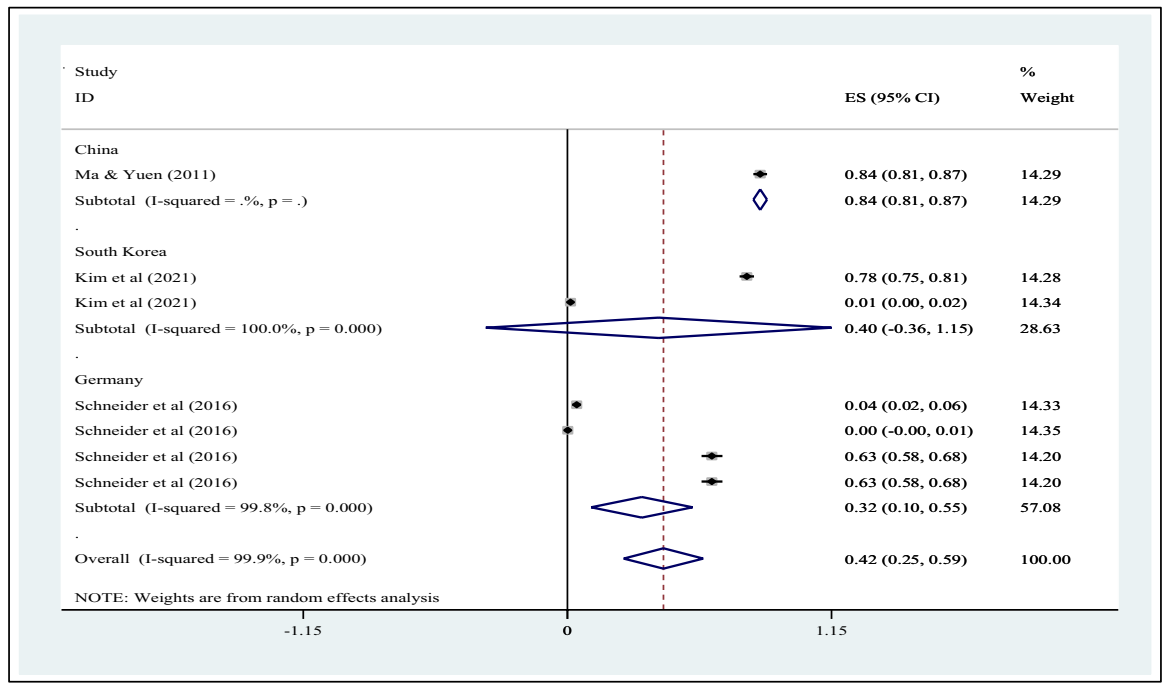

Fig. 8 A forest plot of the effect of behavioral intention in online learning

than random errors $\left(\mathrm{Q}=1990.25, \mathrm{I}^{2}=99.5 \%, \mathrm{p}<.01\right)$. Significant effects were found in the USA $(\mathrm{z}=3.13, \mathrm{p}=0.002)$, Austria $(\mathrm{z}=8.63, \mathrm{p}<.01)$, Australia $(\mathrm{z}=7.46$, $\mathrm{p}<.01)$, China $(\mathrm{z}=5.59, \mathrm{p}<.01)$ and overall results $(\mathrm{z}=5.85, \mathrm{p}<.01)$ (Fig. 9). Thus, we rejected Hypothesis 2: Instruction may not significantly influence other factors in online learning.

\subsection{The effect of engagement in online learning across the world}

We calculated eight effect sizes to study the effect of engagement in online learning from China, Australia, and South Korea. We adopted a random-effect model since the percentage of variance of the effect sizes is due to heterogeneity rather than random errors $\left(\mathrm{Q}=943.42, \mathrm{I}^{2}=99.3 \%, \mathrm{p}<.01\right)$. Significant effects were found in China $(z=2.91, p=0.004)$, Australia $(z=25.68, p<.01)$, South Korea $(z=15.35, p<.01)$, and overall results $(\mathrm{z}=4.22, \mathrm{p}<.01)$ (Fig. 10). Thus, we rejected Hypothesis 3: Engagement may not significantly influence other factors in online learning.

\subsection{The effect of interaction in online learning across the world}

We calculated 32 effect sizes to study the effect of engagement in online learning from Australia, Spain, Turkey, the USA, China, and South Korea. We adopted a random-effect model since the percentage of variance of the effect sizes is due to heterogeneity rather than random errors $\left(\mathrm{Q}=1550.30, \mathrm{I}^{2}=98.0 \%, \mathrm{p}<.01\right)$. Significant effects were found in Australia $(z=3.21, \mathrm{p}<.01)$, Spain $(\mathrm{z}=11.87, \mathrm{p}<.01)$, Turkey $(z=6.27, p<.01)$, the USA $(z=9.20, p<.01)$, China $(z=6.98, p<.01)$, South Korea $(z=9.94, p<.01)$, and overall results $(z=8.55, p<.01)$ (Fig. 11). Thus, we rejected 
Study

ID

$\%$

ES $(95 \% \mathrm{CI}) \quad$ Weight

USA

Baker (2004)

Baker (2004)

Barton et al (2017)

Barton et al (2017)

Subtotal (I-squared $=98.1 \%, \mathrm{p}=0.000)$

Austria

Paechter et al (2010)

Paechter et al (2010)

Paechter et al (2010)

Subtotal $($ I-squared $=92.9 \%, \mathrm{p}=0.000$ )

Australia

Ginns \& Ellis (2007)

Ginns \& Ellis (2007)

Subtotal (I-squared $=0.0 \%, \mathrm{p}=0.678)$

China

Zhang \& Liu (2019)

Zhang \& Liu (2019)

Subtotal (I-squared $=98.6 \%, p=0.000)$

Overall (I-squared $=99.5 \%, \mathrm{p}=0.000)$

NOTE: Weights are from random effects analysis

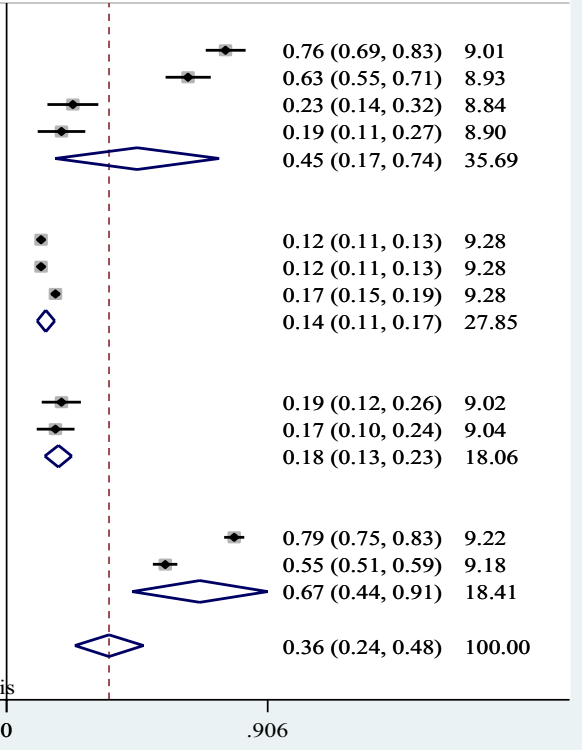

Fig. 9 A forest plot of the effect of instruction in online learning across the world

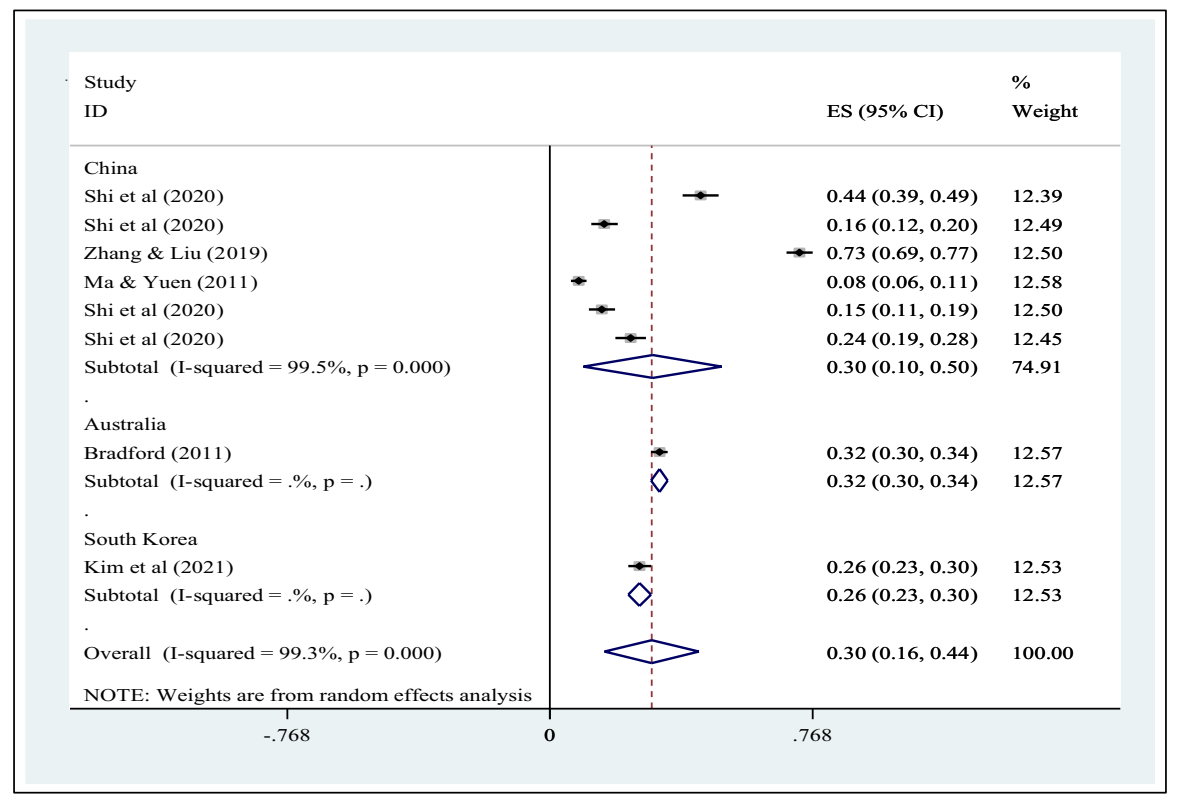

Fig. 10 A forest plot of the effect of engagement in online learning 


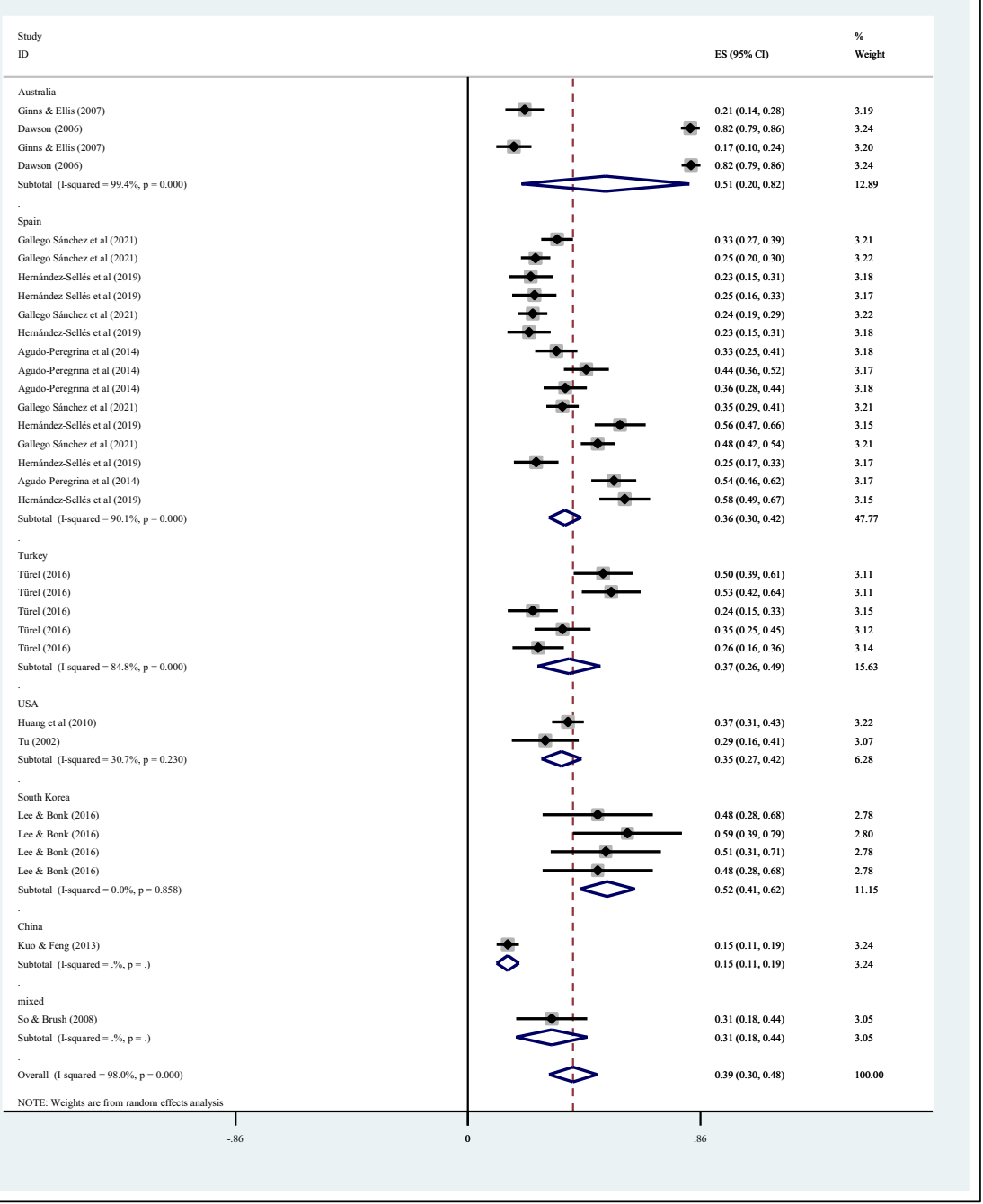

Fig. 11 A forest plot of the effect of interaction in online learning across the world

Hypothesis 4: Interaction may not significantly influence other factors in online learning.

\subsection{The effect of motivation in online learning across the world}

We calculated nine effect sizes to study the effect of motivation in online learning from the USA and China. We adopted a random-effect model since the percentage of variance of the effect sizes is due to heterogeneity rather than random errors $\left(\mathrm{Q}=1785.91, \mathrm{I}^{2}=99.6 \%, \mathrm{p}<.01\right)$. Significant effects were found in the 
USA $(\mathrm{z}=3.49, \mathrm{p}<.01)$, China $(\mathrm{z}=3.34, \mathrm{p}=0.001)$, and overall results $(\mathrm{z}=3.44$, $\mathrm{p}=0.001$ ) (Fig. 12). Thus, we rejected Hypothesis 5: Motivation may not significantly influence other factors in online learning.

\subsection{The effect of self-efficacy in online learning across the world}

We calculated 45 effect sizes to study the effect of self-efficacy in online learning across the world. We adopted a random-effect model since the percentage of variance of the effect sizes is due to heterogeneity rather than random errors $\left(Q=1275.51, I^{2}=96.7 \%, p<.01\right)$. Significant effects were found in Latvia $(\mathrm{z}=61.85, \mathrm{p}<.01)$, China $(\mathrm{z}=16.87, \mathrm{p}<.01)$, Italy $(\mathrm{z}=112.02, \mathrm{p}<.01)$, South Korea $(z=67.57, p<.01)$, the UK $(z=100.98, p<.01)$, Portugal $(z=78.99$, $\mathrm{p}<.01)$, Luxembourg $(\mathrm{z}=77.30, \mathrm{p}<.01)$, the Netherlands $(\mathrm{z}=66.38, \mathrm{p}<.01)$, Mexico $(z=85.27, p<.01)$, Chile $(z=85.68, p<.01)$, France $(z=73.60, p<.01)$, Japan $(z=93.87, p<.01)$, Denmark $(z=82.95, p<.01)$, Slovenia $(z=83.31$, $\mathrm{p}<.01)$, Belgium $(\mathrm{z}=96.29, \mathrm{p}<.01)$, Finland $(\mathrm{z}=95.18, \mathrm{p}<.01)$, Sweden $(\mathrm{z}=69.57, \mathrm{p}<.01)$, Greece $(\mathrm{z}=72.90, \mathrm{p}<.01)$, Australia $(\mathrm{z}=120.54, \mathrm{p}<.01)$, Ireland $(\mathrm{z}=72.80, \mathrm{p}<.01)$, Poland $(\mathrm{z}=64.29, \mathrm{p}<.01)$, Hungary $(\mathrm{z}=79.88$, $\mathrm{p}<.01)$, Iceland $(\mathrm{z}=54.68, \mathrm{p}<.01)$, New Zealand $(\mathrm{z}=65.90, \mathrm{p}<.01)$, Estonia

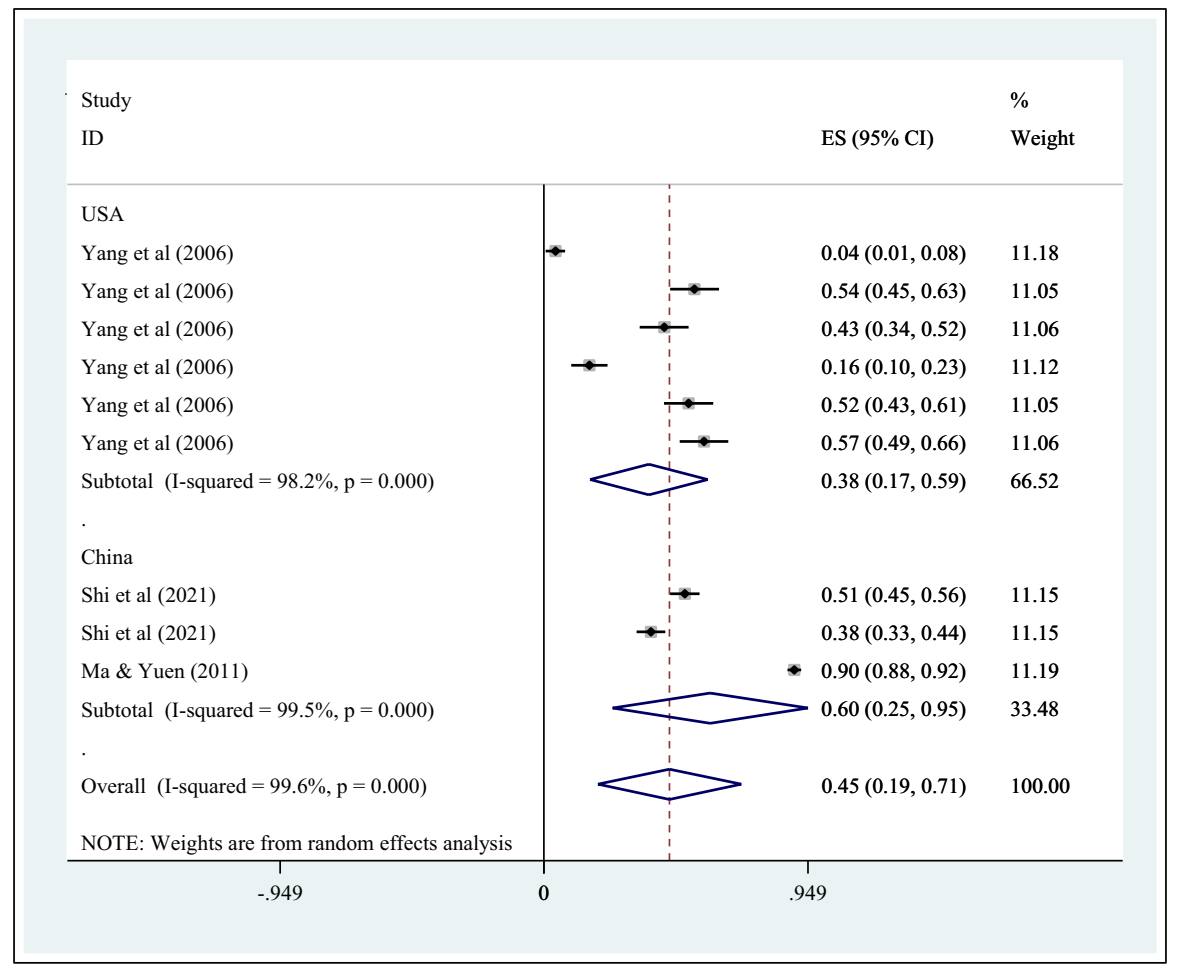

Fig. 12 A forest plot of the effect of motivation in online learning across the world 
$(\mathrm{z}=71.80, \mathrm{p}<.01)$, Switzerland $(\mathrm{z}=78.10, \mathrm{p}<.01)$, Germany $(\mathrm{z}=85.64, \mathrm{p}<.01)$, Czech public $(\mathrm{z}=88.17, \mathrm{p}<.01)$, Slovak Republic $(\mathrm{z}=79.69, \mathrm{p}<.01)$, Austria $(\mathrm{z}=82.05, \mathrm{p}<.01)$, Israel $(\mathrm{z}=88.01, \mathrm{p}<.01)$, and overall results $(\mathrm{z}=75.49$, $\mathrm{p}<.01)$. Thus, we rejected Hypothesis 6: Self-efficacy may not significantly influence other factors in online learning.

\subsection{The effect of performance in online learning across the world}

We calculated 79 effect sizes to study the effect of motivation in online learning across the world. We adopted a random-effect model since the percentage of variance of the effect sizes is due to heterogeneity rather than random errors $\left(\mathrm{Q}=2.0 \mathrm{e}+05, \mathrm{I}^{2}=100 \%, \mathrm{p}<.01\right)$. Significant effects were found in China $(\mathrm{z}=8.52$, $\mathrm{p}<.01)$, Iran $(\mathrm{z}=4.06, \mathrm{p}<.01)$, Australia $((\mathrm{z}=8.75, \mathrm{p}<.01)$, Germany $(\mathrm{z}=2.19$, $\mathrm{p}=0.029)$, the USA $(\mathrm{z}=4.41, \mathrm{p}<.01)$, Spain $(\mathrm{z}=7.45, \mathrm{p}<.01)$, the Netherlands $(\mathrm{z}=3.54, \mathrm{p}<.01)$, Canada $(\mathrm{z}=2.63, \mathrm{p}=0.009)$, Australia $(\mathrm{z}=2.25, \mathrm{p}=0.024)$, Turkey $(\mathrm{z}=8.82, \mathrm{p}<.01)$, and overall results $(\mathrm{z}=8.22, \mathrm{p}<.01)$. Thus, we rejected Hypothesis 7: Performance may not significantly influence other factors in online learning.

\subsection{The effect of satisfaction in online learning across the world}

We calculated 16 effect sizes to study the effect of satisfaction in online learning across the world. We adopted a random-effect model since the percentage of variance of the effect sizes is due to heterogeneity rather than random errors $\left(\mathrm{Q}=1166.46, \mathrm{I}^{2}=98.7 \%, \mathrm{p}<.01\right)$. Significant effects were found in the USA $(\mathrm{z}=4.85, \mathrm{p}<.01)$, South Korea $(\mathrm{z}=15.48, \mathrm{p}<.01)$, China $(\mathrm{z}=6.34, \mathrm{p}<.01)$, and overall results $(\mathrm{z}=6.02, \mathrm{p}<.01)$ (Fig. 13). Thus, we rejected Hypothesis 8: Satisfaction may not significantly influence other factors in online learning.

\subsection{The effect of self-regulation in online learning across the world}

We calculated 24 effect sizes to study the effect of self-regulation in online learning across the world. We adopted a random-effect model since the percentage of variance of the effect sizes is due to heterogeneity rather than random errors $\left(\mathrm{Q}=21,097.06, \mathrm{I}^{2}=99.9 \%, \mathrm{p}<.01\right)$. Significant effects were found in Canada $(\mathrm{z}=3.28, \mathrm{p}=0.001)$, South Korea $(\mathrm{z}=7.85, \mathrm{p}<.01)$, China $(\mathrm{z}=5.92, \mathrm{p}<.01)$, Switzerland $(\mathrm{z}=10.48, \mathrm{p}<.01)$, and overall results $(\mathrm{z}=7.02, \mathrm{p}<.01)$ (Fig. 14). Thus, we rejected Hypothesis 9: Self-regulation may not significantly influence other factors in online learning.

We summarized the hypothesis testing results (Table 1) to improve the readability. We generally rejected all the null hypotheses and concluded that the nine factors could exert significant effects on online learning across the world. 


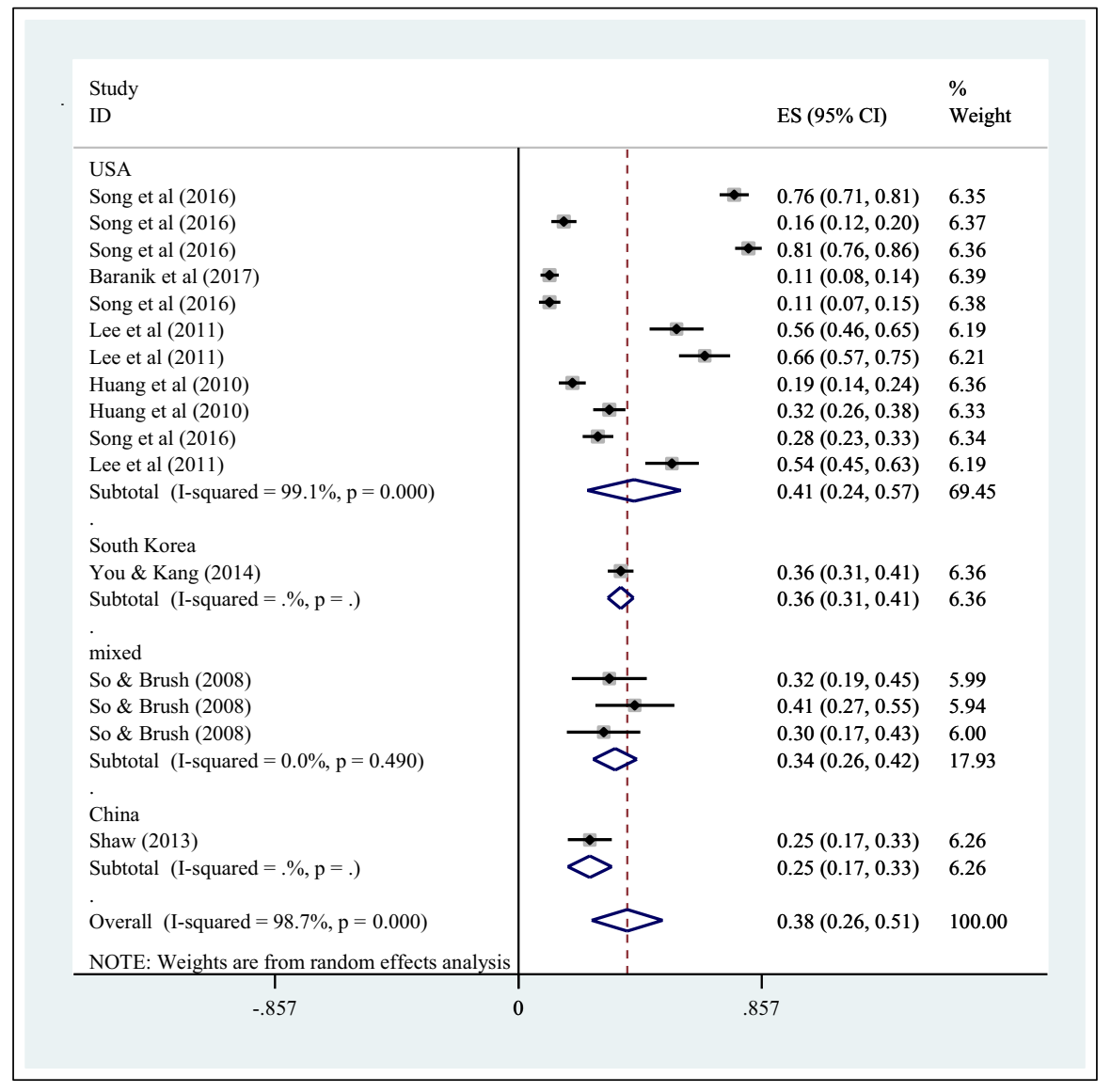

Fig. 13 A forest plot of the effect of satisfaction in online learning across the world

\section{Discussion}

This finding broadly supports the work of other studies in this area linking online learning outcomes with nine variables such as behavioral intention, instruction, engagement, interaction, motivation, self-efficacy, performance, satisfaction, and self-regulation. The unpredictable pandemic has encouraged billions of learners to acquire knowledge through online learning approaches, along with which various online platforms are booming. Those successfully handling nine factors may obtain profitable learning outcomes.

There are also some exceptions in this study. The research authored by Kim et al. (2021) failed to find any significant effect of behavioral intention on online learning in South Korea possibly due to its limitations. The data merely retrieved from self-reported questionnaires based on participants' self-perceptions, whose reliability is dependent on their understandings. The study is also limited to a single 


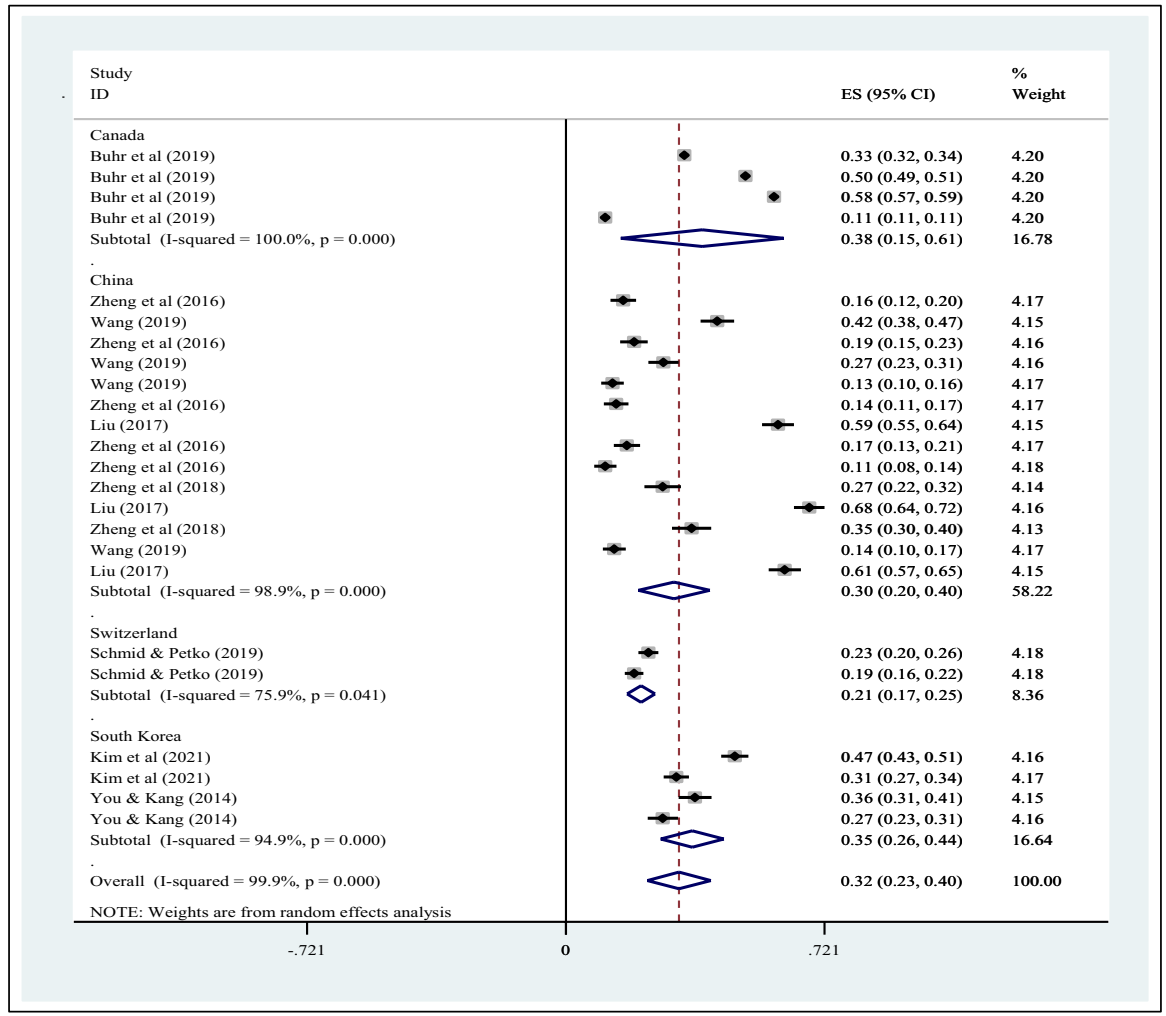

Fig. 14 A forest plot of the effect of self-regulation in online learning across the world

Table 1 Hypothesis testing results

\begin{tabular}{lll}
\hline $\mathrm{N}$ & Hypothesis & Result \\
\hline 1 & $\begin{array}{c}\text { Behavioral intention may be not significantly influenced by other factors in online learn- } \\
\text { ing. }\end{array}$ & Rejected \\
2 & Instruction may not significantly influence other factors in online learning. & Rejected \\
3 & Engagement may not significantly influence other factors in online learning. & Rejected \\
4 & Interaction may not significantly influence other factors in online learning. & Rejected \\
5 & Motivation may not significantly influence other factors in online learning. & Rejected \\
6 & Self-efficacy may not significantly influence other factors in online learning. & Rejected \\
7 & Performance may not significantly influence other factors in online learning. & Rejected \\
8 & Satisfaction may not significantly influence other factors in online learning. & Rejected \\
9 & Self-regulation may not significantly influence other factors in online learning. & Rejected
\end{tabular}

online course, whose results may not be generalizable to other contexts. The pooled diamond is long and has a wide $95 \%$ confidence interval $(r=0.40,95 \%$ confidence interval $=-0.36 \sim 1.15$ ), indicating a lower reliability of the study (Kim et al., 2021). 
Online learning outcomes could be improved by enhancing learners' behavioral intention. Learners with stronger behavioral intention could encourage learners to engage in online learning for longer than those with weaker behavioral intention. With the development of online courses and digital technologies, online learning is increasingly occurring in various educational situations, which presents various profiles of learners' learning psychology and behavior. Online learning can enable students to conduct independent and exploratory learning according to their preferences, and learning behaviors can be naturally presented. The network also provides a carrier to record learners' implicit learning behaviors. These learning behaviors are often unconscious and scattered, and their potential rules are hidden and thus need to be explored to stimulate their behavioral intention of online learning. Compared with the explicit learning behaviors, the implicit ones can better reflect the subtle and complex logical relationship in learning. Researchers and designers of online learning could track and record students' learning behaviors in the online learning platform for further analysis. They can then enhance students' online learning behavioral intention based on the characteristics of their learning behaviors.

Online instruction can be realized through the use of the two-way interactive function of the computer network management technology. On the one hand, the system can track teachers' instruction behaviors, students' learning behaviors, their personal information, learning process, and different instruction stages. On the other hand, teachers can adopt appropriate instructional strategies based on the students' feedback in the system and propose personalized solutions. Instruction may also improve reliant on the posts on the discussion forum where students and teachers can interact with each other and solve various difficult problems. Online instruction is subject to many factors such as timely feedback of the teachers, teachers' technology expertise (Paechter et al., 2010), instructor verbal immediacy (Baker, 2004), teachers' technology habits, teachers' mean fidelity score, teachers' education backgrounds, teachers' online instruction experience (Barton et al., 2017), and teachers' perceived task value (Zhang \& Liu, 2019). Attention to these factors is meaningful to designers and teachers of the online learning approach.

Online learning engagement exerts a great influence on learning effectiveness and instruction quality. There is a positive relationship between self-regulation, satisfaction, learning motivation, and online learning engagement. It is thus necessary to design the online instructional strategies and learning approaches to enhance levels of students' satisfaction, self-efficacy, motivation, self-regulation, and learning engagement. The degree of difficulty of learning contents and learning topics greatly influence students' online learning engagement. Teachers' guidance and instructional design also exert some influence on students' online learning engagement. Teachers could make every effort to improve online instruction design and reduce students' dropout rates. The selection and design of teaching contents and learning tasks should be closely related to learning goals. Learners' interest and demographic information should be fully considered to maintain students' learning motivation, meet students' individual learning needs, and then enhance students' online learning engagement.

Online learners' performance could be improved if we could improve the learning environment, encourage guidance and participation of teachers, optimize designs of 
online learning activities, enrich learning contents, and adopt effective evaluation methods. In online contexts, learning is mostly implemented alone, and learners can't fully control the learning process themselves, because teachers cannot provide direct supervision and guidance. Teachers may not know the specific learning progress and it becomes difficult for teachers to control the whole learning process. Therefore, by improving the teaching management function of the online teaching system, it is feasible to make the system automatically monitor the learning process. Designers and educational institutes could improve the network hardware environment, guarantee the connection speed, and take effective anti-virus measures.

\section{Conclusion}

\subsection{Major findings}

This study identifies nine variables that may exert a significant effect on online learning outcomes during this special pandemic time across the world. The findings may be generalizable to America, Asia, and Europe. Although relatively fewer publications in Africa have been included, the findings could provide a meaningful reference for African researchers, learners, and teachers.

\section{Limitations}

However, with a relatively small sample size, caution must be applied, as the findings might not be applicable to all the countries and areas across the world. We could not include all of the publications due to the limitation of library resources. Those written in languages other than English were not included although English has been the main medium to carry knowledge. There may be other important factors influencing online learning outcomes that were excluded from this study.

\subsection{Future research directions}

The design of future online learning could abide by the principles of educational practice, supported by educational technologies and online pedagogies (Kidd \& Murray, 2020). Future research could include more publications from more diversified backgrounds. Online learning design could also keep pace with the development of information technologies.

Supplementary Information The online version contains supplementary material available at https://doi. org/10.1007/s10639-021-10720-y.

Funding This work is supported by Major National Social Science Project "A Philosophical Reflection on AI and its Logic under the Background of Big Data" (Project Number: 19ZDA041), 2019 MOOC of Beijing Language and Culture University (MOOC201902) (Important) "Introduction to Linguistics", "Introduction to Linguistics" of online and offline mixed courses in Beijing Language and Culture University in 2020, and Research and reform of the "Undergraduate Teaching Reform and Innovation 
Project" of Beijing higher education in 2020 -- innovative "multilingual +" excellent talent training system (202010032003).

\section{Declarations}

The study complies with Ethical Standards.

Conflict of interest The authors declare that they have no conflict of interest.

\section{References}

Al-Rahmi, W. M., Alias, N., Othman, M. S., Marin, V. I., \& Tur, G. (2018). A model of factors affecting learning performance through the use of social media in Malaysian higher education. Computers \& Education, 121(1), 59-72. https://doi.org/10.1016/j.compedu.2018.02.010

Anders, A. (2015). Theories and applications of massive online open courses (MOOCs): The case for hybrid design. International Review of Research in Open and Distance Learning, 16(6). https://doi. org/10.19173/irrodl.v16i6.2185.

Anderson, J. F. (1979). Teacher immediacy as a predictor of teaching effectiveness. In D. Nimmo (Ed.), Communication yearbook (Vol. 3, pp. 543-559). Transaction Books.

Artino, A. R., \& Stephens, J. M. (2009). Beyond grades in online learning: Adaptive profiles of academic self-regulation among naval academy undergraduates. Journal of Advanced Academics, 20, 568-601. https://doi.org/10.1177/1932202X0902000402

Baker, J. D. (2004). An investigation of relationships among instructor immediacy and affective and cognitive learning in the online classroom. Internet and Higher Education, 7, 1-13. https://doi.org/10. 1016/j.iheduc.2003.11.006

Barnard-Brak, L., Lan, W. Y., \& Paton, V. O. (2010). Profiles in self-regulated learning in the online learning environment. International Review of Research in Open and Distance Learning, 11(1), 61-79. https://doi.org/10.19173/irrodl.v11i1.769

Barton, E. A., Whittaker, J. V., Kinzie, M. B., DeCoster, J., \& Furnari, E. (2017). Understanding the relationship between Teachers' use of online demonstration videos and Fidelity of implementation in "MyTeachingPartner-math/science". Teaching and Teacher Education, 67, 189-201. https://doi.org/ 10.1016/j.tate.2017.06.011

Bartsch, A., \& Schneider, F. M. (2014). Entertainment and politics revisited: How non-escapist forms of entertainment can stimulate political interest and information seeking. Journal of Communication, 64, 369-396. https://doi.org/10.1111/jcom.12095

Basal, A., \& Eryilmaz, A. (2020). Engagement and affection of pre-service teachers in online learning in the context of COVID 19: Engagement-based instruction with web 2.0 technologies vs. direct transmission instruction. Journal of Education for Teaching, 47(1), 131-133. https://doi.org/10.1080/ 02607476.2020 .1841555

Begg, C. B., \& Mazumdar, M. (1994). Operating characteristics of a rank correlation test for publication bias. Biometrics, 50(4), 1088-1101. https://doi.org/10.2307/2533446

Ben-Eliyahu, A., Moore, D., Dorph, R., \& Schunn, C. D. (2018). Investigating the multidimensionality of engagement: Affective, behavioral, and cognitive engagement across science activities and contexts. Contemporary Educational Psychology, 53, 87-105. https://doi.org/10.1016/j.cedpsych.2018. 01.002

Blizak, D., Blizak, S., Bouchenak, O., \& Yahiaoui, K. (2020). Students' perceptions regarding the abrupt transition to online learning during the COVID-19 pandemic: Case of faculty of chemistry and hydrocarbons at the University of Boumerdes-Algeria. Journal of Chemical Education, 97(9), 2466-2471. https://doi.org/10.1021/acs.jchemed.0c00668

Bradford, G. R. (2011). A relationship study of student satisfaction with learning online and cognitive load: Initial results. Internet and Higher Education, 14, 217-226. https://doi.org/10.1016/j.iheduc. 2011.05.001

Carrillo, C., \& Flores, M. A. (2020). COVID-19 and teacher education: A literature review of online teaching and learning practices. European Journal of Teacher Education, 43(4), 466-487. https:// doi.org/10.1080/02619768.2020.1821184 
Chen, X., \& Hu, J. (2020). ICT-related behavioral factors mediate the relationship between adolescents' ICT interest and their ICT self-efficacy: Evidence from 30 countries. Computers \& Education, 159, 104004. https://doi.org/10.1016/j.compedu.2020.104004

Chen, N. S., Ko, H. C., Kinshuk, \& Lin, T. (2005). A model for synchronous learning using the internet. Innovations in Education and Teaching International, 42(2), 181-194. https://doi.org/10.1080/ 14703290500062599

Cohen, E. L. (2014). What makes good games go viral? The role of technology use, efficacy, emotion and enjoyment in players' decision to share a prosocial digital game. Computers in Human Behavior, 33, 321-329. https://doi.org/10.1016/j.chb.2013.07.013

Cutumisu, M., \& Lou, N. M. (2020). The moderating effect of mindset on the relationship between university students' critical feedback-seeking and learning. Computers in Human Behavior, 112, 106445. https://doi.org/10.1016/j.chb.2020.106445

Den Brok, P., van Eerde, D., \& Hajer, M. (2010). Classroom interaction studies as a source for teacher competencies: The use of case studies with multiple instruments for studying teacher competencies in multicultural classes. Teachers and Teaching., 16(6), 717-733. https://doi.org/10.1080/13540602. 2010.517689

Egger, M., Smith, G. D., Schneider, M., \& Minder, C. (1997). Bias in meta-analysis detected by a simple, graphical test. BMJ Clinical Research, 315(7109), 629-634. https://doi.org/10.1136/bmj.315.7109. 629

Gallego Sánchez, M. C., De-Pablos-Heredero, C., Medina-Merodio, J. A., Robina-Ramírez, R., \& Fernandez-Sanz, L. (2021). Relationships among relational coordination dimensions: Impact on the quality of education online with a structural equations model. Technological Forecasting and Social Change, 166, 120608. https://doi.org/10.1016/j.techfore.2021.120608

Gittell, J.H., 2009. High performance healthcare, using the power of relationships to achieve quality, efficiency and resilience. McGraw Hill, EEUU.

Grant-Vallone, E. J., \& Ensher, E. A. (2000). Effects of peer mentoring on types of mentor support, program satisfaction and graduate student stress: A dyadic perspective. Journal of College Student Development, 41, 637-642. https://doi.org/10.1080/00140130050174545

Guo, Z., Xiao, L., Van Toorn, C., Lai, Y., \& Seo, C. (2016). Promoting online learners' continuance intention: An integrated flow framework. Information \& Management, 53(2), 279-295. https://doi. org/10.1016/j.im.2015.10.010

Higgins, J.P.T., \& Green, S. (2011). Cochrane handbook for systematic reviews of interventions version 5.1.0 [updated March 2011]. The Cochrane Collaboration 2011. April 13, 2021 Available from www.handbook.cochrane.org

Houston, S. L., II, Brady, K., Narasimham, G., \& Fisher, D. (2017). Pass the idea please: The relationship between network position, direct engagement, and course performance in MOOCs. In Proceedings of the fourth (2017) ACM conference on learning@ scale (pp. 295-298). ACM. https://doi.org/ $10.1145 / 3051457.3054008$.

Huang, J. (2020). Successes and challenges: Online teaching and learning of chemistry in higher education in China in the time of COVID-19. Journal of Chemical Education, 97(9), 2810-2814. https:// doi.org/10.1021/j.jchemed.0c00671

Istenic, A. (2021). Online learning under COVID-19: Re-examining the prominence of video-based and text-based feedback. ETR\&D-Educational technology research and development, 69(1), 117-121. https://doi.org/10.1007/s11423-021-09955-w

Jia, C. Y., Hew, K. F., Bai, S. R., \& Huang, W. J. (2020). Adaptation of a conventional flipped course to an online flipped format during the Covid-19 pandemic: Student learning performance and engagement. Journal of research on technology in education. https://doi.org/10.1080/15391523.2020. 1847220

Jiang, S., Fitzhugh, S. M., \& Warschauer, M. (2014). Social positioning and performance in MOOCs. In Workshop on graph-based educational data mining (Vol.14).http://citeseerx.ist.psu.edu/viewdoc/ download?doi=10.1.1.662.8773\&rep=rep1\&type=pdf retrieved 10 April 2021.

Joo, Y. J., Lim, K. Y., \& Kim, E. K. (2011). Online university students' satisfaction and persistence: Examining perceived level of presence, usefulness and ease of use as predictors in a structural model. Computers \& Education, 57(2), 1654-1664. https://doi.org/10.1016/j.compedu.2011.02.008

Jung, Y., \& Lee, J. (2018). Learning engagement and persistence in massive open online courses (MOOCS). Computers \& Education, 122, 9-22. https://doi.org/10.1016/j.compedu.2018.02.013

Kamble, A., Gauba, R., Desai, S., \& Golhar, D. (2021). Learners' perception of the transition to instructor-led online learning environments: Facilitators and barriers during the COVID-19 pandemic. The 
International Review of Research in Open and Distance Learning, 22(1), 199-215. https://doi.org/ 10.19173/irrodl.v22i1.4971

Kidd, W., \& Murray, J. (2020). The Covid-19 pandemic and its effects on teacher education in England: How teacher educators moved practicum learning online. European Journal of Teacher Education, 43(4), 542-558. https://doi.org/10.1080/02619768.2020.1820480

Kim, D., Jung, E., Yoon, M., Chang, Y., Park, S., Kim, D., \& Demir, F. (2021). Exploring the structural relationships between course design factors, learner commitment, self-directed learning, and intentions for further learning in a self-paced MOOC. Computers \& Education, 166, 104171. https://doi. org/10.1016/j.compedu.2021.104171

Kinzie, M. B., Whittaker, J. V., McGuire, P., Lee, Y., \& Kilday, C. R. (2015). Research on curricular development for pre-kindergarten mathematics \& science. Teachers College Record, 117(7), 070304.

Klein, P., Ivanjek, L., Dahlkemper, M. N., Jelicic, K., Geyer, M. A., Kuchemann, S., \& Susac, A. (2021). Studying physics during the COVID-19 pandemic: Student assessments of learning achievement, perceived effectiveness of online recitations, and online laboratories. Physical review physics education research, 17(1), 010117. https://doi.org/10.1103/PhysRevPhysEducRes.17.010117

Kluger, A. N., \& DeNisi, A. (1998). Feedback interventions: Toward the understanding of a double-edged sword. Current Directions in Psychological Science, 7(3), 67-72. https://doi.org/10.1111/14678721.ep10772989

Lin, T. J. (2021). Exploring the differences in Taiwanese university students' online learning task value, goal orientation, and self-efficacy before and after the COVID-19 outbreak. Asia-pacific education researcher. https://doi.org/10.1007/s40299-021-00553-1

Literat, I. (2021). "teachers act like We're robots": TikTok as a window into youth experiences of online learning during COVID-19. AERA open, 7, 2332858421995537. https://doi.org/10.1177/23328 58421995537

Mayer, R. E., \& Moreno, R. (2003). Nine ways to reduce cognitive load in multimedia learning. Educational Psychologist, 38(1), 43-52. https://doi.org/10.1207/S15326985EP3801_6

McNamara, C. L. (2010). K-12 teacher participation in online professional development (Doctoral dissertation). Retrieved from ProQuest LLC, Educational Doctoral Dissertation, University of California, San Diego and California State University, San Marcos.

Means, B., Toyama, Y., Murphy, R., \& Baki, M. (2013). The effectiveness of online and blended learning: A meta-analysis of the empirical literature. Teachers College Record, 115, 1-47. https://doi.org/ $10.1080 / 10888438.2011 .624566$

Mehrabian, A. (1967). Orientation behaviors and nonverbal attitude communication. Journal of Cоттиnication, 16, 324-332. https://doi.org/10.1111/j.1460-2466.1967.tb01190.x

Moher, D., Liberati, A., Tetzlaff, J., \& Altman, D. G. (2009). Preferred reporting items for systematic reviews and meta-analyses: The PRISMA statement. Annals of Internal Medicine, 151(4), 264-269. https://doi.org/10.14306/renhyd.18.3.114

Moule, P. Pontin, D. Gilchrist, M. \& Ingram, R. (2003). Critical appraisal framework. Retrieved Feb. 8, 2021, http://learntech.uwe.ac.uk/da/Default.aspx?pageid=1445

Paechter, M., Maier, B., \& Macher, D. (2010). Students' expectations of, and experiences in e-learning: Their relation to learning achievements and course satisfaction. Computers \& Education, 54, 222229. https://doi.org/10.1016/j.compedu.2009.08.005

Paxton, C. L. C., Wanless, S. B., \& Rimm-Kaufman, S. E. (2013). Coaching support, context, and fidelity of implementation in responsive classroom ${ }^{\circledR}$ schools. Paper presented at the Society for Research on Educational Effectiveness, Washington, D.C. Abstract retrieved from http://eric.ed.gov/?id=ED563 070 on August 21, 2021.

Pintrich, P. R., \& Schunk, D. H. (2002). Motivation in education: Theory, research, and applications (2nd ed.), upper Saddle River, N.J.: Merrill prentice hall.

Puzziferro, M. (2008). Online technologies self-efficacy and self-regulated learning as predictors of final grade and satisfaction in college-level online courses. American Journal of Distance Education, 22(2), 72-89. https://doi.org/10.1080/08923640802039024

Rahman, M. H. A., Uddin, M. S., \& Dey, A. (2021). Investigating the mediating role of online learning motivation in the COVID-19 pandemic situation in Bangladesh. Journal of computer assisted learning. https://doi.org/10.1111/jcal.12535

Roth, F. S., Weinmann, C., Schneider, F. M., Hopp, F., \& Vorderer, P. (2014). Seriously entertained: Antecedents and consequences of hedonic and eudaimonic entertainment experiences with political 
talk shows on TV. Mass Communication and Society, 17, 379-399. https://doi.org/10.1080/15205 436.2014.891135

Sanchez, R. J., Bauer, T. N., \& Paronto, M. E. (2006). Peer-mentoring freshman: Implications for satisfaction, commitment, and retention to graduation. The Academy of Management Learning and Education, 5, 25-37. https://doi.org/10.5465/AMLE.2006.20388382

Schlenz, M. A., Schmidt, A., Wostmann, B., Kramer, N., \& Schulz-Weidner, N. (2020). Students' and lecturers' perspective on the implementation of online learning in dental education due to SARSCoV-2 (COVID-19): A cross-sectional study. BMC Medical Education, 20(1), 354. https://doi.org/ 10.1186/s12909-020-02266-3

Scott, R. A., Swan, J. E., Wilson, M. E., \& Roberts, J. J. (1986). Organizational behavior modification: A general motivational tool for sales management. Journal of Personal Selling and Sales Management, 6(2), 61-70. https://doi.org/10.1080/08853134.1986.10754427

Shrader, S., Wu, M., \& Owens, D. (2016). Massive open online courses (MOOCs): Participant activity, demographics, and satisfaction. Online learning, 20(2), 199-216. https://doi.org/10.24059/olj. v20i2.596

Siddiq, F., Hatlevik, O. E., Olsen, R. V., Throndsen, I., \& Scherer, R. (2016). Taking a future perspective by learning from the past--a systematic review of assessment instruments that aim to measure primary and secondary school students' ICT literacy. Educational Research Review, 19, 58-84. https:// doi.org/10.1016/j.edurev.2016.05.002

Steelman, L. A., Levy, P. E., \& Snell, A. F. (2004). The feedback environment scale: Construct definition, measurement, and validation. Educational and Psychological Measurement, 64(1), 165-184. https:// doi.org/10.1177/0013164403258440

Suzuki, W., Nassaji, H., \& Sato, K. (2019). The effects of feedback explicitness and type of target structure on accuracy in revision and new pieces of writing. System, 81, 135-145. https://doi.org/10. 1016/j.system.2018.12.017

Terras, M. M., \& Ramsay, J. (2015). Massive open online courses (MOOCs): Insights and challenges from a psychological perspective. British Journal of Educational Technology, 46(3), 472-487. https://doi.org/10.1111/bjet.12274

Thweatt, K. S., \& McCroskey, J. C. (1996). Teacher nonimmediacy and misbehavior: Unintentional negative communication. Communication Research Reports, 13(2), 198-204. https://doi.org/10.1080/ 08824099609362087

Trepte, S., \& Reinecke, L. (2010). Unterhaltung online e motive, Erleben, Effekte [entertainment online e motives, experiences, effects]. In W. Schweiger \& K. Beck (Eds.), Handbuch online-Kommunikation [handbook of online communication] (pp. 211-233). VS Verlag für Sozialwissenschaften.

Tseng, H. H. (2018). Use of e-learning and course assignments to improve learning effectiveness in construction project planning. People: International Journal of Social Sciences, 4(3), 1361-1375. https://doi.org/10.20319/pijss.2019.43.13611375

Van Eck, N. J., \& Waltman, L. (2010). Software survey: VOSviewer, a computer program for bibliometric mapping. Scientometrics, 84(2), 523-538. https://doi.org/10.1007/s11192-009-0146-3

Van Eck, N.J., \& Waltman, L. (2019). VOSviewer Manual: Manual for VOSviewer version 1.6.11. Universiteit Leiden.

Woolfolk, A. (2016). Educational Psychology (13th ed.). Pearson Education.

Wu, B., \& Chen, X. (2017). Continuance intention to use MOOCs: Integrating the technology acceptance model (TAM) and task technology fit (TTF) model. Computers in Human Behavior, 67, 221-232. https://doi.org/10.1016/j.chb.2016.10.028

Yang, C. C., Tsai, I. C., Kim, B., Cho, M. H., \& Laffey, J. M. (2006). Exploring the relationships between students' academic motivation and social ability in online learning environments. Internet and Higher Education, 9, 277-286. https://doi.org/10.1016/j.iheduc.2006.08.002

Yates, A., Starkey, L., Ben, E., \& Flueggen, F. (2020). High school students' experience of online learning during Covid-19: The influence of technology and pedagogy. Technology pedagogy and education. https://doi.org/10.1080/1475939X.2020.1854337

Zhang, S., \& Liu, Q. (2019). Investigating the relationships among teachers' motivational beliefs, motivational regulation, and their learning engagement in online professional learning communities. Computers \& Education, 134, 145-155. https://doi.org/10.1016/j.compedu.2019.02.013

Publisher's note Springer Nature remains neutral with regard to jurisdictional claims in published maps and institutional affiliations. 